\title{
SABER E COMPLEXIDADE COMO FUNDAMENTO EPISTEMOLÓGICO DA PEDAGOGIA E DA CIDADANIA AMBIENTAL ${ }^{1}$
}

\author{
KNOWLEDGE AND COMPLEXITY AS AN EPISTEMOLOGICAL FOUNDATION \\ OF PEDAGOGY AND ENVIRONMENTAL CITIZENSHIP
}

\author{
Carla da Silva Ribeiro ${ }^{2}$, Cadidja Coutinho ${ }^{3}$ e Noemi Boer ${ }^{4}$
}

\section{RESUMO}

Neste estudo, que se caracteriza como uma revisão bibliográfica, de abordagem qualitativa, objetiva-se apontar como o saber ambiental e a complexidade se constituem em fundamento epistemológico da pedagogia e da cidadania ambiental. Para tanto, realizou-se uma investigação em obras e artigos científicos que abordam o tema em questão. $\mathrm{O}$ estudo permite constatar que o saber ambiental deve direcionar-se à resolução de problemas, baseado em valores éticos do saber complexo e em conhecimentos práticos, para viabilizar a reconstrução da ordem socioambiental, a reorganização das bases de produção e a sobrevivência humana. Essa lógica possibilita perceber que a construção da cidadania ambiental, em uma sociedade complexa, é pertinente, a fim de minimizar os problemas ambientais causados pela ação do homem, superar o modelo econômico capitalista, que considera a natureza fonte indiscriminada de recursos. Portanto, é preciso repensar e reelaborar o processo educativo, na medida em que as sociedades se transformam.

Palavras-chave: Educação ambiental, Formação cidadã, Pensamento complexo.

\section{ABSTRACT}

This study, which is characterized as a bibliographic review, with a qualitative approach, aims to point out how environmental knowledge and complexity constitute an epistemological foundation of pedagogy and environmental citizenship. To this end, an investigation was carried out on works and scientific articles that address the topic in question. The study shows that environmental knowledge must be directed towards problem solving, based on ethical values of complex and practical knowledge, in order to make possible the reconstruction of the socio-environmental order, the reorganization of the production bases and human survival. This logic makes it possible to perceive that the construction of environmental citizenship, in a complex society, is pertinent, in order to minimize the environmental problems caused by man, to overcome the capitalist economic model, which considers nature to be an indiscriminate source of resources. Therefore, it is necessary to rethink and rebuild the educational process, as the societies transform themselves.

Keywords: Environmental education, Citizen formation, Complex thinking.

\footnotetext{
${ }^{1}$ Artigo relacionado à dissertação de Mestrado em Ensino de Humanidades e Linguagens da primeira autora, com financiamento PROSUC/CAPES.

${ }^{2}$ Acadêmica do curso de Mestrado em Ensino de Humanidades e Linguagens - Universidade Franciscana - UFN. E-mail: carlazem@gmail.com

${ }^{3}$ Coorientadora - Professora adjunta da Universidade Federal do Pampa - UNIPAMPA Campus Dom Pedrito, RS. E-mail: cadidjabio@gmail.com

${ }^{4}$ Orientadora - Docente do curso de Mestrado em Ensino de Humanidades e Linguagens - Universidade Franciscana - UFN. E-mail: noemiboer@gmail.com
} 


\section{INTRODUÇÃO}

Os problemas ambientais que afetam as sociedades contemporâneas ganham, cada vez mais, proporções significativas em todo mundo. Estudos apontam que, para minimizar os problemas causados pelas ações antrópicas ao meio ambiente, as sociedades terão que adequar seu modo de vida. Isso exige mudanças sociais, culturais, políticas, econômicas, formação de novos valores e humanização. Esse cenário complexo, que exige inúmeras mudanças, resulta novos desafios para a educação e para o trabalho docente.

A complexidade ambiental apresenta amplo entendimento de mundo, introduzindo o limite do conhecimento e da incompletude do ser. Implica saber que a incerteza, o caos e os riscos são, ao mesmo tempo, condição inerente do ser e do saber (LEFF, 2006; MORIN, 2011). A complexidade implica uma revolução do pensamento, mudança de mentalidade, transformação do conhecimento e práticas educativas para a construção do saber e da racionalidade ambiental, que orientam a construção de um mundo de sustentabilidade, de equidade e de democracia (LEFF, 2006). Aprender a aprender sobre e com a complexidade ambiental demanda a compreensão do mundo, que problematiza os conhecimentos e saberes.

Nessa linha de pensamento, o saber ambiental ${ }^{5}$ questiona o conhecimento fragmentado em disciplinas, para sistematizar um campo de conhecimentos teóricos e práticos, direcionado para a rearticulação das relações entre sociedade e natureza (LEFF, 2006). O autor enfatiza que o saber ambiental excede o campo das ciências ambientais, concebidas no enfoque ecológico das disciplinas tradicionais, por exemplo, antropologia ecológica, saúde, economia e engenharia ambiental, e adentra no terreno dos valores éticos, dos conhecimentos práticos e dos saberes complexos, que atendem às necessidades de transformação exigida pela sociedade mundial.

Cabe sublinhar que o pensamento complexo trata da incerteza capaz de conceber a organização. A palavra "complexus significa o que foi tecido junto [...]. A complexidade é a união entre a unidade e multiplicidade" (MORIN, 2011, p. 36). Portanto, existe complexidade quando elementos distintos são inseparáveis, como o econômico, político, sociológico, psicológico, afetivo e mitológico. Nessa lógica, o conhecimento precisa ser visto como uma nova forma de pensamento, ou seja, como ensino transdisciplinar que atenda aos níveis de emergência da realidade, de maneira globalizada, mas também capaz de reconhecer a singularidade do individual. "[...] a ideia de complexidade é que se trata de um pensamento que procura interligar o que está separado; situar o conhecimento no contexto e na globalização" (MARTINAZZO, 2004, p. 51).

Com base no saber e no pensamento complexo, na mediação dos processos de ensino, é preciso considerar o ser humano em sua totalidade. A natureza humana é complexa, constituída, ao mesmo

\footnotetext{
${ }^{5}$ Leff (2007) usa a expressão "saber ambiental" para atribuir novos significados ao saber. Em sua essência, o saber ambiental, descrito por Leff, é coerente ao pensamento complexo ou complexidade, descrito por Morin.
} 
tempo, pelos aspectos físicos, biológicos, psíquicos, culturais, sociais e históricos. Esse entendimento justifica a proposição de uma educação que considere a complexidade humana e seus diferentes saberes, de maneira que estejam interligados, em que um complementa o outro (MORIN, 2011, 2017).

Para Morin (2017), a educação deve estar centrada em cinco (5) finalidades educativas, explicadas no decorrer do texto: uma cabeça bem-feita; ensinar a condição humana; aprendizagem do viver; aprendizagem da incerteza e educação cidadã. O ensino pode ser entendido como "arte ou ação de transmitir os conhecimentos a um aluno, de modo que ele os compreenda e assimile, tem um sentido mais restrito, porque apenas cognitivo" (MORIN, 2017, p. 11). O "ensino educativo" não tem a função de transmitir o simples saber, mas sim a cultura que deve promover a compreensão da condição humana, que ajude a viver, pensar o aberto e o livre (MORIN, 2017).

Nesse sentido, o desafio está na proposição de um ensino que relacione as diferentes áreas do conhecimento, de forma interdisciplinar, pluridisciplinar e transdisciplinar, para que os conhecimentos sejam entendidos como complementares e inseparáveis (MORIN, 2011, 2017). Nessa abordagem, é necessária a superação do modelo fragmentado de ensino, que separa os conhecimentos em disciplinas.

Nessa perspectiva, a educação ambiental se constitui em uma prática educativa transdisciplinar, crítica, reflexiva e humanizadora (LUZZI, 2012; RIBEIRO; BOER, 2019). Esses autores argumentam que a educação ambiental tem a responsabilidade de promover o desenvolvimento de posturas éticas no ser humano em relação ao meio ambiente, ou seja, formação de novos valores e da cidadania, a construção da identidade pessoal, ambas relacionadas à própria experiência social.

A partir dessas considerações iniciais, neste artigo, portanto, tem-se por objetivo apontar como o saber ambiental e a complexidade se constituem em fundamento epistemológico da pedagogia e da cidadania ambiental. Cabe destacar que o saber e a complexidade ambiental constituem o fundamento epistemológico da pesquisa, voltada à elaboração da dissertação de Mestrado em Ensino de Humanidades e Linguagens, da primeira autora, da qual deriva este artigo.

\section{METODOLOGIA}

O delineamento metodológico do estudo caracteriza-se como uma revisão bibliográfica, de abordagem qualitativa. As metodologias de pesquisa qualitativa " são capazes de incorporar a questão do significado e da intencionalidade como inerentes aos atos, às relações e às estruturas sociais" (MINAYO, 2007, p.10). Portanto, o que norteia a pesquisa qualitativa são as ideias centrais do estudo, a escolha adequada dos métodos e de abordagem dos dados.

A pesquisa bibliográfica é um procedimento utilizado nos trabalhos de caráter exploratório-descritivo e "implica um conjunto ordenado de procedimentos de busca por soluções, atento ao objeto de estudo e que, por isso, não pode ser aleatório" (LIMA; MIOTO, 2007, p.38). Segundo essas autoras, o primeiro passo da pesquisa bibliográfica compreende a escolha das opções teóricas 
fundamentais e de uma narrativa teórica. Na seleção do material para a pesquisa bibliográfica, é importante definir: (a) Parâmetro temático: selecionar as obras que tenham relação com os temas do estudo; (b) Parâmetro linguístico: selecionar as obras nos idiomas escritos; (c) Principais fontes: consultar livros, periódicos, teses, dissertações, entre outras; (d) Parâmetro cronológico de publicação: compor o universo a ser pesquisado, definindo o período a ser pesquisado.

Seguindo os parâmetros indicados por Lima e Mioto (2007), as obras selecionadas para este estudo são todas em língua portuguesa, algumas traduzidas, e o período considerado foi 2000 - 2019. Assim, foram selecionadas as seguintes obras: Leff (2006, 2007); Luzzi (2012); Martinazzo (2004, 2016), Morin (2011, 2017); Santos (2005). Além dessas, foram consultados artigos publicados em periódicos e anais de eventos.

A partir das orientações metodológicas da pesquisa bibliográfica, descritas por Lima e Mioto (2007), procedeu-se à leitura dos materiais selecionados, observando-se: (a) Leitura de reconhecimento do material bibliográfico: feita rapidamente para localizar e selecionar o material que pode apresentar informações e/ou dados referentes ao tema; (b) Leitura exploratória: realizada com o objetivo de verificar se as informações e/ou dados selecionados interessavam de fato ao estudo; (c) Leitura seletiva: realizada para determinar o material que, de fato, interessa; (d) Leitura reflexiva ou crítica: feita para considerar o estudo crítico do material do ponto de vista do autor da obra; (e) Leitura interpretativa: realizada para relacionar as ideias expressas, nas obras selecionadas, com o problema para o qual se busca uma resposta.

Os dados levantados, durante o estudo, estão apresentados em três seções, cujas informações sobre o saber e complexidade ambiental, a pedagogia ambiental e a cidadania ambiental são fundamentais e bastante relevantes.

\section{SABER E COMPLEXIDADE AMBIENTAL}

Diante da crise de valores sociais e ambientais em que a sociedade se encontra, a educação ambiental é um processo importante para a formação de novos saberes e conhecimentos relacionados à transformação de realidade social, cultural, econômica, política e ambiental. A educação ambiental existe para articular a formação de conceitos e ideologias com os processos de construção de conhecimentos e saberes, para uma transformação social (LUZZI, 2012; LEFF, 2007).

Nessa linha de pensamento, o saber ambiental emerge do diálogo de saberes e da interdisciplinaridade de conhecimentos, embasa um campo epistemológico que problematiza os paradigmas definidos para estabelecer uma racionalidade ambiental (LEFF, 2006, 2007). De acordo com o autor, a hermenêutica do saber ambiental se constitui como um campo de significados que difunde os sentidos do ambiente e a complexidade, para a construção de um mundo que respeite a diferença e a alteridade. 
Nesse viés, o autor apresenta um conceito de ambiente amplo, multifacetado, maleável e complexo, incorporado por processos de âmbito natural, técnico e social, que pode ser definido como "um conjunto de processos ecológicos, produtivos e culturais, para reconstruir o habitat como transformação complexa das relações entre sociedade e natureza" (LEFF, 2007, p. 287); multifacetado, porque pode ser compreendido a partir de diferentes perspectivas; e maleável, porque, ao ser amplo e multifacetado, pode ser ampliado ou reduzido em conformidade com a necessidade ou interesse dos envolvidos.

Além disso, o conhecimento pertinente deve enfrentar o desafio da globalização e da complexidade, relacionar todas as dimensões, sejam elas humanas, sociais, políticas, econômicas, afetivas, entre outras. Deve reconhecer que não se pode isolar uma parte do todo, nem as partes umas das outras (MORIN, 2011, 2017). Entende-se que o "conhecimento pertinente é o que é capaz de situar qualquer informação em seu contexto" (MORIN, 2017, p. 15).

O saber ambiental surge do espaço gerado pelo desenvolvimento das ciências, centralizadas em seus objetos de conhecimento, e que produz a incompreensão dos processos complexos que não podem ser explicados por essas disciplinas. O discurso ambiental decorre do posicionamento crítico da razão e da lógica capitalista da vida social, que desponta da natureza e do social marginalizado pela racionalidade econômica (LEFF, 2006, 2007).

É oportuno destacar que o saber ambiental não é formado apenas pelas convergências das disciplinas científicas definidas, mas sim pela urgência de um conjunto de saberes teóricos, técnicos e estratégicos. O pensamento complexo e os princípios de racionalidade ambiental informam, por meio de experiências e práticas concretas em cada sociedade e cultura, a partir de suas diversidades (LEFF, 2006, 2007), a necessidade de implementação desses saberes. A racionalidade ambiental se forma da desconstrução da racionalidade capitalista, baseia-se em estratégias para construir uma economia de equidade e de sustentabilidade, que permita às comunidades se desenvolverem a partir de uma gestão participativa e democrática dos recursos naturais.

Os saberes ambientais requerem o diálogo sistemático entre as diferentes ciências, indispensáveis para a compreensão das consequências ecológicas das ações humanas, requerem também conhecimentos para formar sujeitos que saibam lidar com a visão sistêmica e com a interpretação complexa dos fatos da natureza e da sociedade (LEFF, 2003, 2007; LUZZI, 2012). Em consonância a essa definição, os autores expõem que a educação ambiental envolve o processo de conscientização em relação aos aspectos socioambientais emergentes, que estimulam a participação cidadã, aliada à transformação de métodos formativos e de pesquisa.

A complexidade ambiental em que se encontra a sociedade exige nova consciência do ser humano em relação à natureza, reclama a formação de novos conhecimentos por meio de métodos interdisciplinares e princípios da complexidade (LEFF, 2003, 2007). O autor explica que a complexidade ambiental surge da racionalidade ambiental, de novos pensamentos e saberes sobre o mundo, com base no conhecimento, na ciência, na tecnologia, e da articulação entre natureza, técnica e cultura. 
Ou seja, a complexidade ambiental é um processo de reformulação de identidades, de novas visões que se constroem na dialética social, cultural, mas também de reflexões coletivas, de valores comuns e ações solidárias. Aprender sobre a complexidade ambiental é uma pedagogia embasada em aprendizagens dialógicas, multiculturais e significativas, capazes de possibilitar a formação de novos saberes, novas identidades, valores democráticos e princípios de sustentabilidade (LEFF, 2003, 2007).

Assim, de acordo com o autor, a complexidade ambiental abre caminho sobre a reflexão quanto à natureza do ser, do saber e do conhecer; sobre a hibridização entre conhecimentos na interdisciplinaridade e transdisciplinaridade; sobre o diálogo de saberes e sobre a incorporação da subjetividade de valores, dos interesses nas tomadas de decisão e procedimentos de apropriação da natureza. Ainda, questiona a maneira como os valores transpõem o conhecimento de mundo, como concede espaço para o encontro entre moral e racional, entre racionalidade formal e a racionalidade substantiva.

Perante os "métodos da complexidade" que despontam da ecologia e da cibernética, que evidenciam a realidade como sistema de inter-relações, interdependências, interações e retroalimentações, o pensamento dialógico favorece a diversidade do ser humano, o confronto de interesses que norteia o processo de estruturação da racionalidade ambiental (LEFF, 2003, 2007). O modelo da complexidade, em que a ordem e a desordem, a ambiência e a ambivalência apresentam-se juntas, desafia educadores a pensarem de forma complexa o processo de ensino e aprendizagem, de maneira que seja mais interessante para alunos e professores (STOCHERO; DIAS; BOER, 2019).

Vale explicar o que foi exposto na introdução deste estudo. Para Morin (2017), a educação deve estar centrada em cinco (5) finalidades educativas. Segundo o autor, a cabeça bem-feita nos concede aptidão para organizar os conhecimentos, os quais nos permitem ligar os saberes e dar a eles sentido, para expor e tratar os problemas. Ensinar a condição humana nos permite reconhecer o ser humano enquanto ser físico, biológico, psíquico, cultural, social e histórico, porque é necessário que o homem tenha conhecimento e consciência de sua complexidade (MORIN, 2017).

Com relação à aprendizagem do viver, o autor argumenta que o objetivo da educação não é transmitir maior número de conhecimentos possíveis, mas sim de criar transformação mental e sabedoria. Para essa aprendizagem, o processo educativo deve se direcionar para a incerteza, isto é, ensinar princípios de estratégias para enfrentar imprevistos, o inesperado, já que a sociedade vive em constante transformação (MORIN, 2017, 2011). Por fim, a educação cidadã tem o preceito de contribuir para a autoformação do homem e para ensiná-lo a ser um cidadão solidário e responsável democraticamente, ao mesmo tempo em que procura, nos aspectos político, cultural, social, histórico e religioso, essas mesmas condições.

A partir da consciência ambiental, são gerados novos princípios, valores e conceitos para uma racionalidade produtiva de desenvolvimento social, humano e civil. Assim, inicia-se uma perspectiva ao progresso do conhecimento, o qual problematiza paradigmas da ciência, questiona ideologias e a relação entre natureza e cultura, consciência e comportamento social (LEFF, 2007). 
Dessa maneira, entende-se que o saber ambiental transforma os conhecimentos e estabelece novos objetos interdisciplinares de formação, novos campos de aplicação e novos processos sociais, os quais são elaborados a partir do processo de conscientização, de formação teórica e de pesquisa cientifica. Portanto, é preciso repensar e reelaborar o processo educativo, na medida em que a sociedade se transforma para contemplar a pedagogia ambiental.

\section{PEDAGOGIA AMBIENTAL}

O paradigma da complexidade propõe práticas pedagógicas que atendam às mudanças na sociedade, a partir de uma teia de conhecimentos sistêmicos ou holísticos, que considera o homem em sua totalidade, que busca superar a visão fragmentada do conhecimento e que promove a formação de um ser humano, ético, humano e sensível (BEHRENS, 2008; STOCHERO; DIAS; BOER, 2019). Para esses autores, o paradigma da complexidade caracteriza-se pela abordagem dialógica, que considera a transformação social, a fim de viabilizar aprendizagens significativas, críticas e reflexivas de alunos e professores.

Nesse entendimento, o ensino deve superar o modelo tradicional de reprodução de conhecimentos, dando abertura à pesquisa, para que o aluno seja protagonista de sua própria aprendizagem. Nessa concepção, o ensino está centrado na relação aluno-professor e não no professor-aluno. O conteúdo a ser conhecido é discutido conjuntamente de maneira dialógica. Portanto, a superação do modelo tradicional de ensino é a primeira condição para a formação de cidadãos que participem da construção de uma sociedade mais justa e igualitária.

O ensino, centrado no aluno, marca também a pedagogia ambiental, que se fundamenta no pensamento da complexidade e considera o saber culturalmente organizado. A complexidade está nas interações entre sujeito e cultura, nas interpretações sobre o mundo e a natureza, na construção de saberes significativos. Pressupõe o entrelaçamento de conhecimentos científicos, saberes populares, prática social individual e coletiva, também busca métodos para compreender a complexidade do processo de ensino e aprendizagem (LEFF, 2003, 2007; LUZZI, 2012).

A pedagogia ambiental estabelece que, no processo educativo, devem ser considerados a complexidade do sujeito; a gestão que entenda a escola como um sistema democrático; métodos de ensino que desenvolvam conhecimentos críticos, reflexivos e pertinentes à realidade complexa da sociedade (LUZZI, 2012). Por fim, conforme o autor, a pedagogia ambiental reclama a formação de professores reflexivos e críticos.

A pedagogia ambiental estabelece diálogo entre a pedagogia crítica e o pensamento complexo, na procura de métodos para entender a complexidade dos processos de ensino e aprendizagem (LUZZI, 2012). Na verdade, uma complexidade que abarque todas as dimensões e áreas de estudo. Nessa linha de raciocínio, para Leff (2007), a pedagogia do ambiente se baseia em experiências concretas com o 
meio físico e social, a fim de promover a formação da consciência, saberes e responsabilidades. $\mathrm{O}$ autor considera o ambiente como fonte de aprendizagem, possibilidade de consolidar as teorias na prática, uma nova racionalidade para a construção de um novo saber. Com base nesse entendimento, Leff (2007) explica a pedagogia da complexidade ambiental, e Luzzi (2012) amplia esse entendimento para a escola e a sala de aula complexa.

Nesse viés, a pedagogia da complexidade ambiental certifica que aprender o mundo depende do ser de cada sujeito, um processo dialético, construído com base na racionalidade e em um possível consenso de sentidos e verdades (LEFF, 2003). Além disso, a pedagogia da complexidade ambiental reconhece o conhecimento de mundo como potência e possibilidade, compreende que a realidade é resultado de uma construção social, impulsionada por valores, interesses e utopias da sociedade. A pedagogia da complexidade está fundamentada na ação solidária, na construção de um saber e racionalidade ambiental, na concretização das potencialidades da natureza. Então, a escola deve preparar as novas gerações para compreender as complexas inter-relações entre o ser humano, natureza e ambiente, gerar saberes e habilidades inovadoras para lidar com o imprevisto, ou seja, para promover a formação cidadã.

A escola complexa, apresentada por Luzzi (2012), é constituída por múltiplas dimensões de aprendizagem, que cada sujeito constrói; é um complexo sistema inseparável de suas interdependências no âmbito institucional, seja de sala de aula, seja de tarefa acadêmica. A escola é um sistema dinâmico e conflitivo, que necessita ser organizado em prol de um objetivo comum, com a finalidade de alcançar o resultado estabelecido. Dispõe, ainda, que os alunos aprendem por meio de conteúdos ofertados pelos professores, pelas interações sociais que ocorrem na escola e na sala de aula.

$\mathrm{Na}$ sala de aula complexa, considera-se que a aprendizagem resulta das interações de diferentes componentes: alunos e professores, seus sentimentos, desejos, angústias; as regras sociais que regulamentam as relações entre seus sujeitos (a liderança e o contrato pedagógico do professor, estabelecido com os alunos); a comunidade de ensino com a qual os alunos se relacionam na sala de aula; a aprendizagem construída por professores e alunos a partir de múltiplas inter-relações e pelo planejamento e gestão em sala de aula (LUZZI, 2012).

Nessa linha de pensamento, entende-se que a escola deve instigar alunos a aprenderem, professores a ensinarem, pais e comunidade escolar a participarem do processo de construção da cidadania de seus alunos, por meio de um ensino que possibilite e considere as vivências, experiências, emoções. A partir dessa perspectiva, os sujeitos envolvidos no processo de ensino são entendidos como parte de um todo.

A educação escolar deveria proporcionar a formação do conhecimento pertinente, estruturado no entendimento da complexa realidade. Em vista disso, entender a realidade sob o enfoque da complexidade significa olhá-la, analisá-la e interpretá-la com base nos princípios do conhecimento complexo e do pensamento científico (MORIN, 2011; MARTINAZZO, 2016). 
Os autores entendem que o conhecimento pertinente é aquele que leva em consideração os princípios da complexidade. Baseado na teoria de Morin, Martinazzo (2016) salienta que são três os princípios da complexidade: o hologramático ou holográfico; o dialógico e o anel recursivo. O princípio hologramático ou holográfico denota que as partes só podem ser compreendidas a partir do todo. O princípio dialógico corrobora que a ordem e a desordem estão relacionadas à própria organização. O terceiro princípio, para entender a complexidade, é o anel recursivo, que vai ao encontro da ideia linear de causa e efeito, uma vez que, na realidade, produtos e efeitos podem ser causadores de suas causas.

Surge, então, a pedagogia ambiental que corrobora com as descrições supracitadas. Compreende-se, por pedagogia ambiental, uma visão educativa mais complexa da educação no que se refere à complexidade do sujeito, à organização escolar, às metodologias de ensino e aprendizagem, à formação e valorização dos professores. A pedagogia ambiental requer métodos de ensino que promovam a contrução de conhecimentos críticos, reflexivos e pertinentes, que possibilitem minimizar os problemas socioambientais em âmbito local e global (LUZZI, 2012; RIBEIRO; BOER; COUTINHO, 2020). Segundo esses autores, os processos de ensino devem desenvolver as capacidades dos sujeitos de problematizar e analisar as demandas apresentadas pela sociedade, na dimensão econômica, política, social, cultural, ambiental, entre outras.

Nessa perspectiva, compete à pedagogia ambiental o desafio de promover um ensino transversal, direcionado à construção de conhecimentos que sejam entendidos como complementares e inseparáveis, que considere a complexidade humana e seus diferentes saberes de maneira que um complemente o outro (RIBEIRO; BOER; COUTINHO, 2020). Enfim, um ensino que integre conhecimentos, saberes e valores necessários à formação da cidadania ambiental.

É desejável que os professores, em suas práticas pedagógicas, façam adequação dos conteúdos curriculares às metodologias de ensino, que possibilitem transformações necessárias à sociedade contemporânea. Essas transformações serão viáveis por meio do desenvolvimento de uma nova postura do ser humano em relação à natureza e ao meio ambiente, o que requer um novo entendimento de mundo a partir da cidadania ambiental.

\section{CIDADANIA AMBIENTAL}

A degradação ambiental gerada pela globalização impôs novas demandas para a educação, com enfoque de internalizar valores e princípios de cidadania no ser humano. Nesse contexto, surge a educação ambiental como práxis pedagógica complexa, dada a necessidade de reforçar a ideia de que as questões sociais se encontram interligadas às questões ambientais. A educação ambiental, dada a complexidade da sociedade, requer processos educativos voltados à construção da cidadania, aos conhecimentos críticos e reflexivos das questões sociais e ambientais (SAHEB; RODRIGUES, 2007). 
Para Luzzi (2012), o termo cidadania apresenta um conceito ampliado, que vai além do exercício do voto. O autor explica que a cidadania abrange diferentes esferas, como, por exemplo, a participação comunitária, que considera as novas formas de ação coletiva na sociedade civil; a participação na sociedade da informação, que pode ser denominada de cidadania informativa; a necessidade de a sociedade consumir em menor escala, o que está atrelado à cidadania do consumo, entre outras.

Diante dos impactos gerados pela sociedade moderna, há de se repensar a cidadania no viés ambiental. Em vista disso, a cidadania começou a assumir novas dimensões no contexto ambiental. A cidadania ambiental, como passou a ser denominada, não pode ser separada dos diversos problemas socioambientais, e esses problemas não podem ser separados dos problemas herdados do desenvolvimento globalizado da sociedade (SANTOS, 2005).

Dessa forma, a cidadania ambiental exige uma análise crítica da reestruturação política, social, econômica e ambiental frente às mudanças da sociedade complexa, ou seja, mudanças nas relações entre sociedade e Estado, nas relações entre os indivíduos de diferentes grupos sociais, no modo de produção, consumo, individualismo, competitividade (SANTOS, 2005). A degradação do meio ambiente é uma questão emergente que a escola precisa tratar na transversalidade do currículo (KOPPE; BOER, 2014; BRASIL, 2018).

A educação ambiental deve promover a formação de cidadãos democráticos e éticos, comprometidos com o coletivo, com o presente e o futuro do planeta (KOPPE; BOER, 2014). As autoras explicam que a educação ambiental, como parte integrante e necessária à formação do indivíduo, deve direcionar-se à resolução de problemas, baseada na ética, na solidariedade, na equidade e justiça, para o desenvolvimento de um sujeito crítico, reflexivo e atuante em sociedade.

A cidadania ambiental demanda um novo contrato social, pressupõe negociações frente a controvérsias, mudanças sociais e ambientais, exige novas relações do homem com a natureza (LUZZI, 2012; SANTOS, 2005). A cidadania, numa sociedade democrática, busca encontrar o equilíbrio entre justiça e sentimentos de pertencimento à comunidade política (LOBATÓN, 2017).

Desse modo, apoiado pela abordagem sociológica da cidadania e da filosofia política, a cidadania é entendida com base em uma perspectiva multidimensional, isto é, possui diferentes dimensões, ou seja, legal, política, social, econômica e intercultural, articuladas umas às outras (LOBATÓN, 2017). Do ponto de vista social, a cidadania é uma instituição histórica que foi construída ao longo do tempo e não se restringe ao que dispõe a lei, pelo qual um indivíduo recebe direitos e deveres dentro de um estado. De acordo com o autor, as diferentes dimensões demostram que a cidadania não se reduz a uma discussão da etimologia do termo, está relacionada aos processos pelos quais os indivíduos conquistaram seus direitos, para viverem, de maneira mais justa, em uma comunidade política.

A cidadania não se reduz apenas ao âmbito da filosofia moral, entendida como as relações de convivência entre cidadãos em uma comunidade política. Nas abordagens de cidadania, encontra-se um conceito jurídico, um ideal político igualitário, regulamentos de lealdade e coexistência política 
entre seus membros (LOBATÓN, 2017). O autor esclarece que as dimensões da cidadania democrática abrangem as interações entre o Estado democrático e o cidadão, entre cidadãos de um mesmo grupo político, permitindo a existência de coletividades que interagem, que se complementam em aspectos econômicos, sociais e culturais, coexistentes numa comunidade política.

Sendo assim, a educação precisa contribuir para a autoformação do ser humano e ensinar como se tornar um cidadão (MORIN, 2017; LUZZI, 2012). Segundo Morin (2017), um cidadão em uma democracia é definido por sua solidariedade e responsabilidade com sua pátria. Por esse lado, a cidadania ambiental exige a participação responsável de seus cidadãos, a articulação nas relações entre sociedade e natureza, a conscientização do dever de defender todas as formas de vida e o meio ambiente (SANTOS, 2005).

Por outro lado, a educação deve incluir as quatro tendências da ecologia, ou seja, ambiental, social, mental e integral ou profunda. Uma educação que discuta o lugar do ser humano na natureza e na complexa teia cósmica, que eduque para viver em harmonia com a natureza, que proponha repartir, com equidade, com os demais seres humanos, os recursos culturais e do desenvolvimento (BOFF, 2018) é uma educação ecológica que, verdadeiramente, prepara para a vida. Percebe-se que os aportes da epistemologia ambiental progridem para a inclusão da perspectiva complexa, autorreflexiva e emancipatória da ciência social crítica, para o estabelecimento de uma racionalidade que abrange o sujeito e seus preconceitos (LEFF, 2006; LUZZI, 2012).

Segundo Luzzi (2012), a educação ambiental é resultado do diálogo entre educação, demandas sociais e contexto histórico. O autor reconhece a escola como um ambiente complexo e dinâmico de ensino, compreende o conhecimento como um processo inacabado, entende a interdependência metodológica de abordagem para conceber a compreensão do complexo mundo que nos rodeia. De acordo com Freire (2011), é preciso que o educador tenha consciência de que é um ser inacabado, que aprende por toda a vida. "Mulheres e homens se tornaram educáveis na medida em que se reconheceram inacabados" (FREIRE, 2011, p.57).

Desse modo, deve-se procurar sempre por uma educação ética, de responsabilidade e de cuidado com o futuro da humanidade. Educar para a formação da cidadania ambiental demanda novos métodos de ensino, superação de uma visão reducionista de ensino e aprendizagem, construção de saberes complexos à transformação social, com o propósito único e seguro de zelar pela sobrevivência da humanidade.

\section{CONSIDERAÇÕES FINAIS}

O objetivo central deste estudo é apontar como o saber ambiental, frente à complexidade humana, pode contribuir para a formação da cidadania ambiental.

Entende-se que as instituições de ensino, quanto aos currículos de ensino e quanto aos professores, no planejamento e desenvolvimento das práticas pedagógicas, devem considerar o ser humano 
em sua complexidade, constituído, ao mesmo tempo, pelo físico, biológico, psíquico, cultural, social e histórico, com o justo propósito de possibilitar a formação de saberes complexos que atendam às necessidades de transformação, exigidas pela sociedade mundial.

Verifica-se que o saber ambiental deve direcionar-se à resolução de problemas quanto a valores éticos, saberes complexos e conhecimentos práticos, todos necessários à reconstrução da ordem socioambiental, à reorganização das bases de produção e sobrevivência humana. Frente à sociedade complexa, o saber ambiental é fundamental para minimizar os problemas ambientais causados pela ação do homem e superar o modelo econômico capitalista, que considera a natureza como fonte de recursos explorados indiscriminadamente.

O estudo demostra que a cidadania ambiental implica conhecimentos, responsabilidade, prudência e a participação de seus cidadãos na tomada de decisões na esfera social e ambiental. Desse modo, a cidadania ambiental poderá resultar novos saberes, a fim de minimizar os problemas ambientais causados pela ação do homem e, assim, superar o modelo econômico capitalista e individualista.

Enfim, a cidadania ambiental requer a preservação dos recursos naturais, a equidade, a solidariedade, nova postura do ser humano frente ao meio ambiente, mudança local de amplitude global. Portanto, é preciso repensar e reelaborar o processo educativo, na medida em que as sociedades se transformam, a fim de promover os saberes necessários à sobrevivência do ser humano no planeta.

\section{REFERÊNCIAS}

BEHRENS, M. A. Paradigma da complexidade: metodologia de projetos, contratos didáticos e portfólios. 2. ed. Petrópolis, RJ: Vozes, 2008.

BOFF, L. Sustentabilidade: o que é: o que não é. 5.ed. rev. e ampl. Petrópolis, RJ: Vozes, 2016.

BRASIL. Ministério da Educação e Cultura. Base Nacional Comum Curricular, 2018. Disponível em: http://basenacionalcomum.mec.gov.br/. Acesso em: 02 mar. 2020.

KOPPE, H. J. S.; BOER. N. Pedagogia Ambiental: concepções de professores e estudantes dos anos iniciais do Ensino Fundamental. Disciplinarum Scientia. Série: Ciências Humanas, Santa Maria, v. 15, n. 2, p. 175-192, 2014. DOI: https://doi.org/10.37780/ch.v15i2.1778

LEFF, E. A complexidade ambiental. São Paulo, SP: Cortez, 2003.

. Epistemologia ambiental. 4. ed. São Paulo, SP: Cortez, 2006. 
Saber ambiental: sustentabilidade, racionalidade, complexidade, poder. 5. ed. Petrópolis, RJ: Vozes, 2007.

LIMA, C. S. de; MIOTO, R.C. T. Procedimentos metodológicos na construção do conhecimento científico: a pesquisa bibliográfica. Katál. Florianópolis, v. 10 n. esp. p. 37-45, 2007.

LOBATÓN. P. R. Los problemas y deafíos actuales de la formación ciudadana. Palabra y Razón, Universidad Católica del Maule, n. 11, p. 27-40, jul. 2017. Disponível em: https://bit.ly/3mT4t6q. Acesso em: 27 jan. 2020.

LUZZI, D. Educação e meio ambiente: uma relação intrínseca. Barueri, SP: Manole, 2012.

MARTINAZZO, C. J. A utopia de Edgar Morin: da complexidade à concidadania planetária. 2. ed. Ijuí, RS: Unijuí, 2004.

MARTINAZZO, C. J. A construção de conhecimentos pertinentes na educação escolar com base no paradigma da complexidade. In: MARTINAZZO, C. J.; BARBOSA, M. G; DRESCH, Ó, I. (orgs.) A educação escolar em um mundo complexo e multicultural. Ijuí, RS: Unijuí, 2016.

MINAYO, M.C.S. O desafio do conhecimento: pesquisa qualitativa em saúde. SP: Hucitec, 2007.

MORIN, E. A cabeça bem-feita: repensar a reforma, reformar o pensamento. 23. ed. Rio de Janeiro, RJ: Bertrand Brasil, 2017.

MORIN, E. Os sete saberes necessários à educação do futuro. 2. ed. São Paulo, SP: Cortez, 2011.

RIBEIRO, C. S; BOER, N. Educação ambiental na educação infantil: relato de uma prática pedagógica em escola de Santa Maria. In: SIMPÓSIO DE ENSINO, PESQUISA E EXTENSÃO, 11, 2019, Santa Maria, RS. Anais [...]. Santa Maria, RS: UFN, 2019, p. 1-10. Disponível em: https://bit.ly/32nDmJ4. Acesso em: 22 jan. 2020.

RIBEIRO, C. S; BOER, N. COUTINHO, C. Marcos regulatórios e pressupostos teóricos da educação ambiental: um estudo de revisão bibliográfica. Research, Society and Development, v. 9, n. 3, e148932563, 2020. DOI: http://dx.doi.org/10.33448/rsd-v9i3.2563 
SAHEB, D; RODRIGUES, D. G. A contribuição da complexidade de Morin para as pesquisas em educação ambiental. Rev. Eletrônica Mestr. Educ. Ambient. Rio Grande, Edição especial XVI Encontro Paranaense de Educação Ambiental, p. 191-207, set. 2017. DOI: https://doi.org/10.14295/ remea.v0i0.7139

STOCHERO, A. D.; DIAS, C. N.; BOER, N. O paradigma da complexidade e a metodologia de Projetos: um estudo de revisão teórica. Disciplinarum Scientia. Série: Ciências Humanas, Santa Maria, v. 20, n. 1, p. 23-33, 2019. DOI: https://doi.org/10.37780/ch.v20i1.2965 